\title{
Alginate-modified Cassava Fiber Loaded Palladium for Electochemical Paracetamol Analysis
}

\author{
Haobing Shi ${ }^{1}$, Yuhong Zheng ${ }^{2}$,Hassan Karimi-Maleh ${ }^{3,4,5}$ and Li Fu ${ }^{1, *}$ \\ ${ }^{1}$ Key Laboratory of Novel Materials for Sensor of Zhejiang Province, College of Materials and \\ Environmental Engineering, Hangzhou Dianzi University, Hangzhou, 310018, PR. China \\ ${ }^{2}$ Institute of Botany, Jiangsu Province \& Chinese Academy of Sciences (Nanjing Botanical Garden \\ Mem. Sun Yat-sen), Nanjing 210014, PR. China \\ ${ }^{3}$ School of Resources and Environment, University of Electronic Science and Technology of China, \\ P.O. Box 611731, Xiyuan Ave, Chengdu, PR. China \\ ${ }^{4}$ Department of Chemical Engineering and Energy, Laboratory of Nanotechnology, Quchan University \\ of Technology, Quchan, Iran \\ ${ }^{5}$ Department of Chemical Sciences (formerly Department of Applied Chemistry), University of \\ Johannesburg, P.O. Box 17011, Doornfontein Campus, Johannesburg 2028, South Africa \\ *E-mail: fuli@hdu.edu.cn
}

Received: 5 June 2021 / Accepted: 19 July 2021 / Published: 10 September 2021

It is required that the content of paracetamol in an individual capsule should not exceed $325 \mathrm{mg}$, thus the accurate detection of paracetamol content in drugs is essential for controlling the quality of drugs and ensuring the safety of patients. Electrochemical methods are easy to operate and low cost with no requirement of complex pre-treatment, which greatly reduces the detection time. The most widely used electrochemical method for the determination of paracetamol content is the application of the chemically modified electrode. In this work, alginate-modified cassava fibers were adopted as a substrate with palladium immobilized and used for the modification of glassy carbon electrode, and the kinetic processes of paracetamol on the electrode surface and the electrochemical behavior under different $\mathrm{pH}$ conditions were investigated. This modified electrode has a very high sensitivity to paracetamol and is capable of making linear detection at $10-370 \mu \mathrm{M}$, with the limit of detection calculated to be $1.2 \mu \mathrm{M}$.

Keywords: paracetamol; analytical chemistry; drug analysis; electrochemistry; cassava fiber; alginate

\section{$\underline{\text { FULL TEXT }}$}

(C) 2021 The Authors. Published by ESG (www.electrochemsci.org). This article is an open access article distributed under the terms and conditions of the Creative Commons Attribution license (http://creativecommons.org/licenses/by/4.0/). 